\title{
Applications of the low-background gamma spectroscopy to the geographical origin of marine salts and prunes
}

\author{
F. Perrot \\ Centre d'Etudes Nucléaires de Bordeaux Gradignan \\ Chemin du Solarium, Le Haut Vigneau, BP120, 33175 Gradignan, France
}

\begin{abstract}
The low background gamma spectroscopy has been applied to try to sign the geographical origin of the French atlantic marine salts and of the prunes from Agen. Most of the activity measurements have been done using low background Ge spectrometers located in Bordeaux. Results have shown that a clear signature exists in the case of the French atlantic salts using the ${ }^{40} \mathrm{~K},{ }^{137} \mathrm{Cs}$ and ${ }^{226} \mathrm{Ra}$ isotopes but not in the case of the prunes.
\end{abstract}

Keywords: radioactivity, low background gamma spectroscopy, geographical origin of marine salts and prunes PACS: $29.30 . \mathrm{Kv} ; 07.85 . \mathrm{Nc}$

\section{INTRODUCTION}

Since more than 10 years, the NEMO (Neutrino Ettore Majorana Observatory) group of the CENBG has been involved in the development of very low background gamma spectrometers to measure the radio-purity of the materials. The sensitivity of these detectors is 4 or 5 orders of magnitude lower than the level of natural radioactivity. With such sensitivity, these spectrometers have revealed to be also very interesting in other disciplines than physics.

As a first example, measurements of a series of Bordeaux wines have shown traces of ${ }^{137} \mathrm{Cs}(<1 \mathrm{~Bq} / 1)$ whose the activity is varying as a function of the year. This has led to the possibility to date wines and eventually to detect frauds [1]. In this paper, we will present two other applications of this technique which have been carried out in collaboration with the DGCCRF (Direction Générale de la Concurrence, de la Consommation et de la Répression des Fraudes), a food and drug agency and the EPOC (Environnements et Paléoenvironnements OCéaniques), a laboratory of the University of Bordeaux. It will concern the geographical origin of the French marine salts in a first part and the prunes from Agen in a second one part.

\section{LOW BACKGROUND GAMMA-RAY SPECTROMETRY}

Most of the samples have been measured with low background gamma-ray spectrometers located in the basement of a 5 -floor building at the University of Bordeaux. The cover of $2.5 \mathrm{~m}$ of concrete (6 mwe) is enough to drastically reduce the hadronic component (secondary protons and neutrons) of the cosmic rays but has almost no effect on the muonic flux. The figure 1 gives a schematic view of the shielding surrounding the Ge crystal. First, the passive shielding is composed from inside to outside of a $5 \mathrm{~cm}$ thick internal roman lead, a $8 \mathrm{~cm}$ thick borated polyethylene and a $10 \mathrm{~cm}$ thick external standard lead. The role of the borated polyethylene is to moderate and capture the neutrons induced on the external lead by the remaining cosmic rays. Moreover, an active shielding composed of two large plastic scintillators coupled to photomultipliers is installed and gives a further reduction by a factor $\sim 3$ of the background. Within these experimental conditions, the total counting rate is about 13 counts $/ \mathrm{mn}$ for a $300 \mathrm{~cm}^{3}$ welltype detector and about 5 counts $/ \mathrm{mn}$ for a $100 \mathrm{~cm}^{3}$ coaxial-type detector in the energy range [30-3000 keV]. The sensitivity of these spectrometers is around $1 \mathrm{mBq} / \mathrm{kg}$ and $10 \mathrm{mBq} / \mathrm{kg}$ respectively for the well-type and coaxial crystals, depending of the isotope and of the nature of the sample (geometry, density, presence of ${ }^{40} \mathrm{~K}$, etc). Few samples with extremely weak radioactivity levels are usually sent to the LSM to be measured with ultra low background gamma spectrometers described in ref.[2]. 


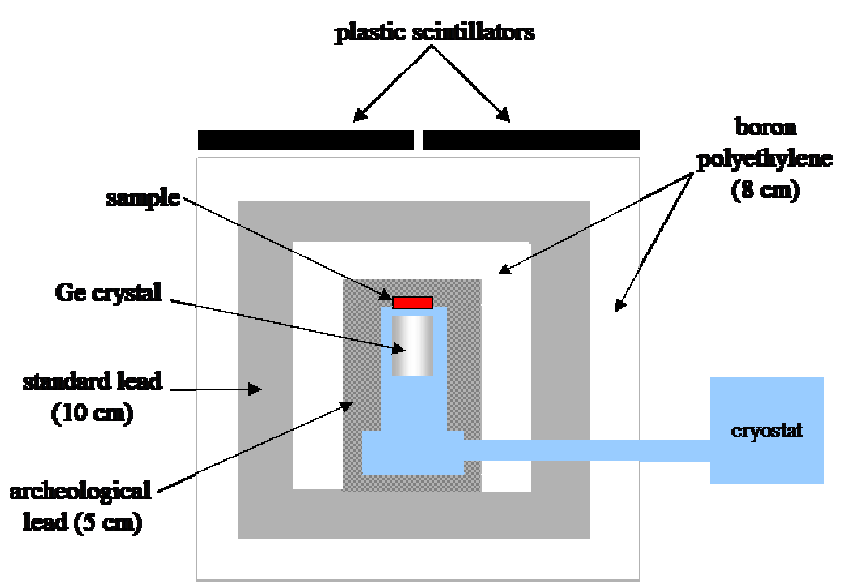

FIGURE 1. Schematic view of the set-up used for low background gamma spectrometry measurements in Bordeaux.

\section{GEOGRAPHICAL ORIGIN OF ATLANTIC MARINE SALTS}

This study has been initiated by the DGCCRF to check the reliability of the label written on various commercial marine salts. The aim is to find a way to discriminate between the French atlantic salts from other atlantic salts (Spain, Portugal...). Indeed, the French atlantic salts, mainly collected in Guérande and in the islands of Ré and Noirmoutier, are protected by a quality control label. Note that it exists also salt "flowers" in the French atlantic salts, supposed to have a better taste for cooking and thus to be more expensive, that have been also investigated.

The salts are only dried and put in a plastic box. Typical mass of a sample is around $100 \mathrm{~g}$. The measurements are performed with a $100 \mathrm{~cm}^{3}$ coaxial-type Ge detector during a typical acquisition time of one week $(\sim 160 \mathrm{~h})$. The figure 2 shows a partial gamma spectrum obtained with a salt from the island of Ré. We observe the characteristic gamma rays from ${ }^{40} \mathrm{~K},{ }^{226,228} \mathrm{Ra},{ }^{228} \mathrm{Th}$ and ${ }^{137} \mathrm{Cs}$ isotopes.

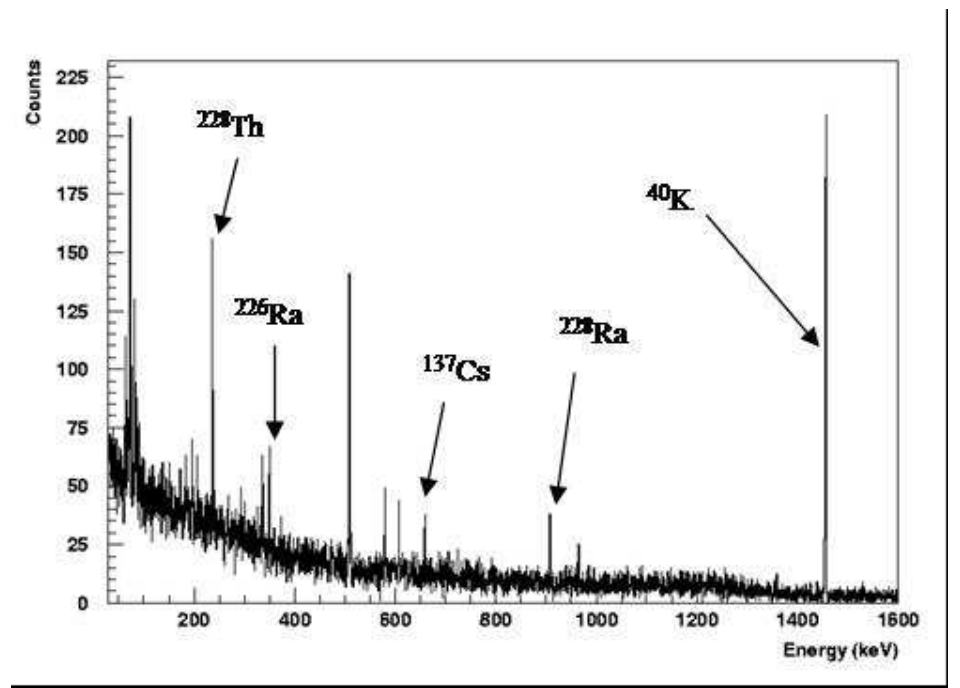

FIGURE 2. Gamma spectrum of a salt from the island of Ré.

The two-dimensional plot of the ${ }^{226} \mathrm{Ra}$ activity as a function of the ${ }^{40} \mathrm{~K}$ activity is given in figure 3 . For the 21 samples of the French atlantic salts, the average activities in ${ }^{226} \mathrm{Ra}$ and ${ }^{40} \mathrm{~K}$ are around $400 \mathrm{mBq} / \mathrm{kg}$ and $40 \mathrm{~Bq} / \mathrm{kg}$ respectively. For the 8 samples from Spain and Portugal, all the ${ }^{226} \mathrm{Ra}$ activities have been found below the level of sensitivity $(<50 \mathrm{mBq} / \mathrm{kg})$, whereas the ${ }^{40} \mathrm{~K}$ activities are in the range of 0 to $15 \mathrm{~Bq} / \mathrm{kg}$, much lower than the French salts. As a result, there is a clear discrimination between these different atlantic salts. This conclusion is reinforced 
by the fact that all the French samples contain traces of ${ }^{137} \mathrm{Cs}$ with activities in the range of 30 to $160 \mathrm{mBq} / \mathrm{kg}$ while the Spanish and Portuguese values are all below the level of sensitivity $(<20 \mathrm{mBq} / \mathrm{kg})$.

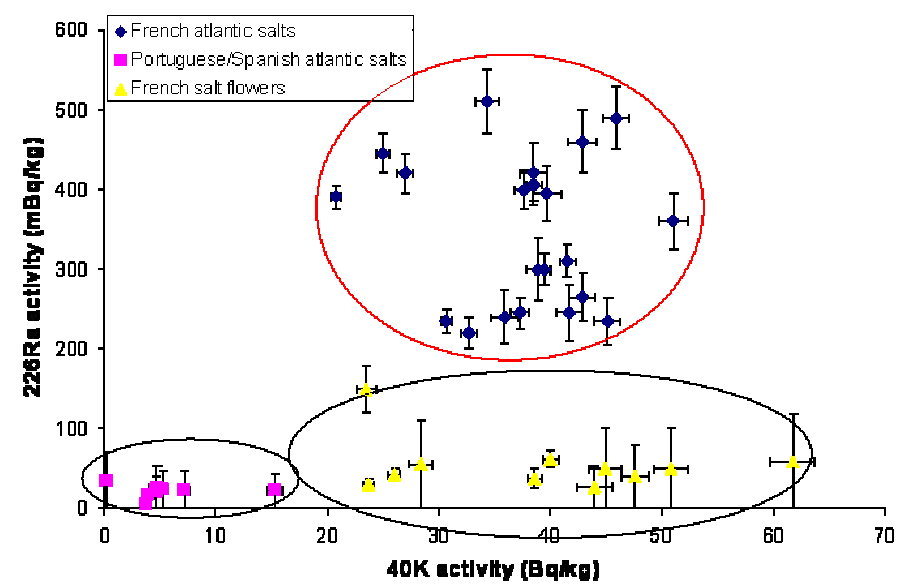

FIGURE 3. Distribution of ${ }^{226}$ Ra activities vs. ${ }^{40} \mathrm{~K}$ activities for all the samples.

In addition, the results from the 11 French atlantic salt flowers are shown in figure 4 . For them, the ${ }^{40} \mathrm{~K}$ activities follow the same distribution as for the French salts while the ${ }^{226} \mathrm{Ra}$ activities are all except one lower than 100 $\mathrm{mBq} / \mathrm{kg}$. For the ${ }^{137} \mathrm{Cs}$ activities, all the samples are also below the sensitivity of the $100 \mathrm{~cm}^{3}$ Ge spectrometer in Bordeaux. However, 4 samples have been re-measured with a $400 \mathrm{~cm}^{3}$ LSM detector leading to positive and more precise values both for the ${ }^{226} \mathrm{Ra}$ and ${ }^{137} \mathrm{Cs}$ activities. Again, we observe a clear discrimination between the standard French atlantic salts and salt flowers.

\section{GEOGRAPHICAL ORIGIN OF PRUNES}

The study of the prunes has also been initiated by the DGCCRF many years ago [3]. Prunes from Agen are protected by a quality control label delivered by the European commission and called IGP (Identification Géographique Protégée). Other countries like Chile or Argentina use the label "Pruneaux d'Agen" because they argue that the prunes they product belong to the same variety of plum tree called "Prune d'Ente". The DGCCRF laboratory has already performed different analyses on the form of prunes cores and on the mineral element distributions with the result they can discriminate the geographical origin with a $90 \%$ level confidence. The problem is that most of the prunes that are exported by others countries are coreless, increasing the possibility of ambiguities. Therefore, we were asked by the DGCCRF if gamma radioactivity measurements on the pulp of the prunes may bring complementary information.

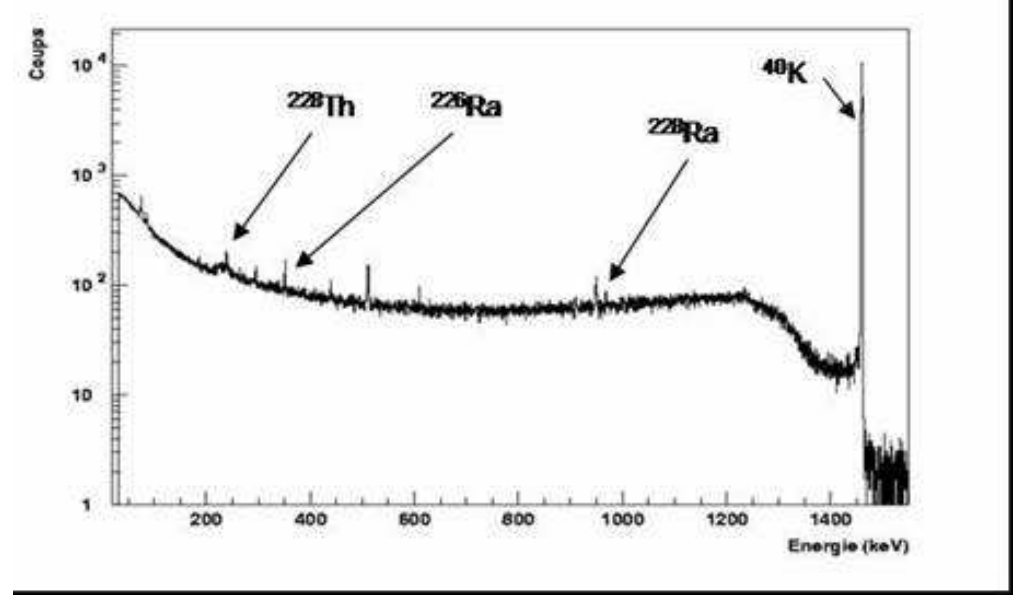

FIGURE 4. Gamma spectrum of a sample of prunes from Agen. 
The 18 samples of prunes have been collected by the DGCCRF: 12 from the region of Agen, 3 from Chile and 3 from Argentina. The pulp is dried and burned into 2-3 g of ashes and put in an airtight tube adapted to the well-type Before any measurements, we wait 2 or 3 weeks in order to reach the secular equilibrium in the ${ }^{226} \mathrm{Ra}$ decay. The figure 4 illustrates the partial gamma spectrum of a sample of prunes from Agen during a typical acquisition time of one week. What is very striking on this spectrum is the huge intensity of the ${ }^{40} \mathrm{~K}$ peak even with a logarithm scale. For all the samples, the activity is rather constant whatever the origin with an average value of $300 \mathrm{~Bq} / \mathrm{kg}$, which is probably a characteristic of the variety called "Ente". Thus, the ${ }^{40} \mathrm{~K}$ is not a good criterion to discriminate the geographical origin. Furthermore, it is responsible of an important background due to the Compton diffusion and the bremsstrahlung effect (the ${ }^{40} \mathrm{~K}$ is also a pure beta emitter at $90 \%$ ) that limits the sensitivity for all the other isotopes. Therefore, the gamma connected to the ${ }^{226,228} \mathrm{Ra},{ }^{228} \mathrm{Th}$ and ${ }^{137} \mathrm{Cs}$ decays are small peaks on a huge Compton background which explains that all the measurements have to be done at least during one week of statistics.

The figure 5 represents the distribution of the ${ }^{226} \mathrm{Ra}$ activity for all the samples.. These results show that the prunes coming from Chile and Argentina have a rather constant activity around $40 \mathrm{mBq} / \mathrm{kg}$. while the prunes from Agen, present a broader distribution with activities between $30 \mathrm{mBq} / \mathrm{kg}$ and $140 \mathrm{mBq} / \mathrm{kg}$. Although the number of samples for all countries is rather limited in this preliminary study, it appears that the ${ }^{226} \mathrm{Ra}$ activity gives already a poor signature of the origin. Similar distributions are also observed for the ${ }^{228} \mathrm{Ra},{ }^{228} \mathrm{Th}$ and ${ }^{137} \mathrm{Cs}$ isotopes leading to similar conclusions.

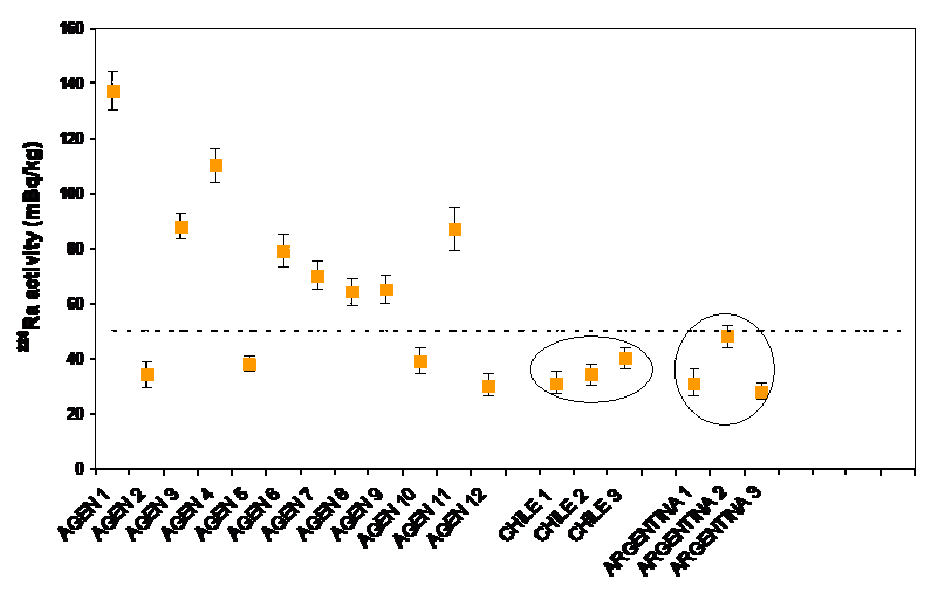

FIGURE 5. Distribution of the ${ }^{226}$ Ra activity as a function of the samples.

\section{CONCLUSION}

The low background gamma-ray spectrometry has been applied to try to sign the geographical origin of some foodproducts, i.e. the French atlantic marine salts and the prunes from Agen. For the salts, the activity measurements of the ${ }^{40} \mathrm{~K}$, ${ }^{137} \mathrm{Cs}$ and ${ }^{226} \mathrm{Ra}$ isotopes give a clear discrimination between salts from different atlantic countries and are even able to discriminate usual salts with salt flowers. For the prunes, the activity measurements are more difficult due to the high potassium content and do not seem to be relevant in that case.

\section{ACKNOWLEDGMENTS}

I would like to thank Ph. Hubert and A. Nachab (CENBG), S. Schmidt (EPOC), B. Médina and J. Gaye and N. Desplat (DGCCRF) for their important contribution to this work.

\section{REFERENCES}

1. Ph. Hubert et al., Annales des falsifications, de l'expertise chimique et toxicologique, 94, 2001, p. 357.

2. Ph. Hubert, see the proceedings.in the same LRT2006 conference, Aussois, 2006

3. J. Gaye, B. Médina (private communication) 